\title{
Curating Sonic Laboratories
}

\author{
Laura Plana Gracia \\ UAL - LCC - CRISAP \\ London \\ laura@netzzz.net
}

\begin{abstract}
Bruno Latour's essay Give Me a Laboratory and I will Raise the World (1983), describes the laboratory as the place in science and technology where innovation happens. From the depth of the lab, the society is so directly modified. This essay examines the power of the laboratory to transform society, or of rebuilding the system in which it is embedded. Following such reasoning, this essay will make a case for how transformations in culture, capital and society that occurred during the 1990s are part of the history from which to explain the emergence of laboratory spaces such as hackerspaces, media labs and the lessfavoured sonic laboratories. Nevertheless, there are qualitative as well as quantitative differences between such places. Since their appearance, sonic laboratories have been aligned, for example, with critical and alternative practices, thus indicating a separation from the neoliberal economies of private sector galleries and established cultural institutions in the public sector (Jaron Rowan, 2015).
\end{abstract}

Reacting against these, the sonic laboratory is often characterised by using open source and digital media and focuses on radically transforming production denouncing how capitalistic market speculates with the value of art objects. The sonic lab offers a

confrontation with the methods of capitalistic technologies, becoming its production more affordable and also, provides models of collaborative practices which encourage experimentation and creativity in the curation of sound arts. The sonic lab offers practices of instrument making that make production more personal but located in a community. Such labs can address new institutional opportunities in humanities to engage with practice-based knowledge creation and extend their mission to include tools, techniques and a new curatorial scope.

Hackerspace, media lab, science, technology, sound art, sonic laboratories.

\section{INTRODUCTION: LABORATORIES IN THE ART, SCIENCE AND TECHNOLOGY NETWORK.}

The most common and well-known definition of "laboratory" is related to science and also, through laboratory studies (LS), which emerge as a mix of science and sociology. LS study the lab but from a sociological point of view. LS analyse the context of the laboratory's production and how it affects and is related to society. LS reached a turning point with the works of Latour, Lynch and Knorr Cetina. Latour and Woolgar who researched in a biochemistry laboratory-made critical contributions to the network of laboratory studies.

Latour and Woolgar were based at the Salk Institute in southern California, while Knorr Cetina worked at the University of Berkeley. Latour, who seemed unaware of the sociology of science and who never seemed interested in science, adopted a "naïve" ethnographic approach to understand laboratory activity. Differently, the German sociologist Karin Knorr Cetina studied a biochemistry laboratory in Berkeley and looked into the informal, practical reasoning of researchers in a work situation. According to Andrew Pickering (1992), LS analysed science as both "practice and culture", as opposed to the study of scientific theories and ideas. Nonetheless, a laboratory is also a place of scientific production but insufficiently explored. The laboratory is a sort of standard organisation of "knowledge society" with the ability to act on the world of objects. Its dynamism arises from its capacity to reconfigure entities from the natural to the social world.

Following, Dominique Vink (2007) defines the laboratory as a reconfiguration space and so coincides with Latour, who remarks the transformative capabilities of the lab, from nature to society. Also, Vink defines the laboratory space as an active system. Laboratories are made up of human groups that are more fluid than the industrial and bureaucratic organisations. As 
Verena Kuni (2005) observes, the laboratory constitutes the "framework for the scientific examination of a phenomenon" and also a "place of transgression".

Following Bruno Latour (1983), it exists a division between organisations, institutions, public policy, on the one hand, and scientific disciplines on the other. So, a lack of understanding of different opinions leads to extreme internalism in science. Latour's position is to demonstrate that laboratories are built to destabilise the difference between macro and micro, inside and outside. In this manner, Latour studied the reception and success of Pasteur's laboratory in 1881, which made more progress and set up "in-site". Then the laboratory "in-site" was transferred back to the workplace at Ecole Normale Superieure. Since then, the scientist in this lab talked with more authority, becoming an imposition to the other lab's needs, and amplifying the interest of external agents. "Suddenly people were manipulating new objects and so acquiring new skills in a new idiosyncratic ethic", says Knorr Cetina (1981). Pasteur's laboratory applied what is known as imitated variation. The success of it is because of a double movement, from the lab to the site, and from the site to the lab, adding the manipulation of new materials. However, how can the laboratory practice be extended? Only by extending the laboratory by itself. Extended into a village, from the lab to the site, to the city, it is an extension of the lab to the outside. However, for the media, it was not seen as a practical movement; it was a prophecy. What the press validated was the inside/outside relation, but in reality, there was a step after step, an event that was possible, but not a miracle. Mystified versions of scientific activity come from overlooking at it. Such displacement of laboratories became a national miracle when it was not.

However, Latour states that the lab is a moment in a dynamic process. The laboratory modifies all other actors, including society. In the beginning, there was distrust in science because of the separation and differentiation of the inside/outside. However, now, there is no differentiation. In science and technology, innovation happens in the laboratory. From the depth of the lab, the society is so directly modified. This states the power of the lab to transform society, rebuilding the system in which is embedded. The transformation of society operated in laboratories, which are places that also renew politics, alter the composition of society because of the very content of the trials made within their walls.

What Latour proposes here is a definition of the laboratory, which relapses in its transformative social capacity. Labs have political strength, and sociological studies have found that what makes science so successful is the way it expresses through texts and inscriptions. What is interesting here is how the strength is gained in laboratories to transform and displace societies. To understand the reason why people pay so much for laboratories which are ordinary places is that these are places of technological devices that invert the hierarchy of forces in society. Making instructions readable and visible, permits the accumulation of knowledge, and that is a condition for acceleration in society.

Latour defines the way we approach science and how sociological science ignores the transformative capacity that labs have. Because laboratories make the relevant changes to happen, we may remember as well that is the universality of society which permits this construction of social change. That is why Latour (1983) expresses the sentence "Give me a laboratory and I will move society".

Lab in science identifies as a place for doing experiments which resemble reality. However, from the 1970s, a surge of the interest in the notion of lab sets it as a space in the culture. With its production, culture constructs society. What the laboratory does is to erase this complicated difference between inside/outside and works to reshape society in innovative conditions. That is what gives prestige to the labs and makes grow their economic potential, which at the same time grows technological capabilities. Moreover, the production of written instructions transforms the lab into a place of culture with literature instrumentation that allows interfering socially.

\section{THE EMERGENCE OF DIY LABORATORIES}

The transformations in culture, capital and ecology in the late 1990s contextualise the history for the emergence of do-it-yourself (DIY) laboratories, hackerspaces, media labs, and sonic laboratories. From the depth of the lab, the society is so directly modified and defines the power of the lab to transform society, rebuilding the system in which is embedded. As Latour (1987) says in Science in Action, there is a division of labour between scholars studying organisations, institutions, public policy on the one hand, and people studying inside scientific disciplines on the other. Therefore, is why this lack of connection in between humanities and scientific process in the laboratory lead towards a highly scientific-technological society based on models of unsustainable development, representing the last phase of techno-capitalism, ideologically alienated with neoliberalism.

Although, since the 1990s, certain practices aligned with critical and alternative practices indicating separation from the neoliberal economies of private sector galleries and established cultural institutions in the public sector, as Jaron Rowan defends in Cultura Libre de Estado (2015). 
Reacting against the privatisation policies, laboratories are often characterised by using opensource and digital media and focus on radically transforming the production denouncing how capitalist market speculates with the value of art objects. These laboratories offer a confrontation with the methods of capitalistic technologies, making the production more affordable, and offering models of collaborative practices which encourage experimentation and creativity. Following Joasia Krysa (Media Art Histories, 2016) "such labs can address new institutional opportunities in humanities to engage with practicebased knowledge creation and extend their mission to include tools, techniques and a new curatorial scope".

The techniques used in these laboratories depend to a great extent on the free distribution on the Internet, and also, the open-source community that favours the use and clone of programs publishing tools and hardware schemes. Open software uses techniques such as a fork. According to Pete Bratach's Why Do Open Source Projects Fork? (2017) open-source software projects start with the intention of creating technology, used for the greater good of the technical and global community. At times like this, project participants start thinking about a fork. Also, in hardware development and musical instrument creation, the publication of schematics and instructions on how to create your own instruments are available to all on the Internet and also in publications such as Nicolas Collins, Handmade Electronics (2006).

\section{MEDIA LABS, LABS IN ACADEMIA AND COUNTER-LABORATORIES}

The lab in the academic environment differs from the scientific and the artistic laboratory. The academic lab has existed mainly since the 1980s with the example of the MIT Media Lab in Massachusetts. The lab in academia arises from the need to merge research and science, but in turn, opens the possibility to research arts and humanities.

The role media art will play in the diffusion of the lab in academia will also extend the role of the laboratory not only in the academy but also in the social level, expanding the laboratory to the structures of art institutions and also citizenship. One can also link the laboratory in academia to the media lab. Since the 1980s, the technical advance of the computational tools, for example, the ARPA network in American universities, made possible and necessary the investment in new media through research. These two factors are crucial in the emergence of media labs: research and innovation. So, the work with new technologies finds much support in the media art sector with a boom of festivals, art centres and institutions during the 1980s. Thus the media lab is closely linked to the academy, but it is also a generator of the media art practices.

According to Romero-Frias (2017), media labs exist in a university environment. These are spaces for digital and social innovation. Media labs are a link between society and academy, spaces of cocreation and collaboration. Their character, educational and promotional, highlights the investigation and experimentation in new methodologies for education. One example of media labs and laboratories' origins in academia was in 1896 when John Dewey founded the Laboratory School, a school linked to the University of Chicago in which experimental approach lead educational innovation. Dedicated to experimentation with technology and social mediation, and thanks to the rapid democratisation and access to technology, labs such as MIT developed in the mid-1980s. However, Ruiz-Martín and Alcalá-Mellado (2016) state how other activities link to lab development but not connected to academia:
"Pioneering labs to other previous initiatives in the sixties were: Experiments in Art and Technology (EAT) (New York, 1963), Center for Advanced Visual Studies (Cavs) (Massachusetts, 1967) and Generative Systems (Chicago, 1968)".

Atau Tanaka (2011), Professor of Media Computing at Goldsmiths, states how the rapid democratisation of technology has made the media labs' technological profile to adopt a social perspective. Tanaka continues stating how the university media labs are intended to serve as a link between society and academia, becoming a space for co-operation and citizen collaboration. Closely related to teaching and dissemination character, media labs serve as a twoway channel through which citizens and researchers influence each other and share knowledge. Tanaka highlights the research profile of university media labs, being an engine of educational, social and digital innovation. The media lab in the academic set up profiles itself as the ideal place for experimentation, testing of new methodologies and educational formulas with citizen participation. According to Tanaka, various forms of media lab have emerged and distinguishes the following:

(i) Industry labs. Labs based on the model of research and development (R\&D) laboratories maintained by companies. For example, Bell Labs and IBM.

(ii) Media art labs. Laboratories where artistic experimentation develops through technology. Including European projects such as Ars Electronica Futurelab (Linz) 
and ZKM Centre for Art and Media (Karlsruhe).

(iii) University labs. Laboratories generated in the university environment focused on innovation and entrepreneurship. One example of them is Experimental Media and Performing Arts Center (EMPAC) at the Rensselaer Polytechnic Institute in New York.

(iv) Citizen labs. Laboratories with social involvement and based on citizen participation with a DIY philosophy. One of the primary examples is the Medialab Prado in Madrid, referent in Spain.

More new forms, such as hack labs, maker spaces, fab labs, city labs, are added to the complex laboratory landscape. Under the name "lab", we can find proposals with very different values. Tanaka points out that the changes undergone by European universities, following the Bologna process, have promoted the emergence of centres with a more experimental nature. Some examples of university lab are Medialab Helsinki (Aalto University) or Paragraphe (Université Paris 8). Another centre is Nebrija Medialab (Facultad de Comunicación de la Universidad Nebrija).

From an academic perspective, the place of these centres generates problems when placing them within institutional structures, although the origin is in disciplinary spaces such as departments and faculties but in search of an institutional legitimation. The same happens in the context of other public institutions, such as Medialab Prado and the difficulty of its ascription within the city council of Madrid, as manifested by its director, Marcos Garcia (2015).

The development of the media labs in the university environment generates new opportunities for innovation, incorporating the hacker spirit, according to Himanen (2003). Digital transformation, openness and social involvement take on a new infrequent dimension in higher education institutions. The media labs coexist with other management approaches that prioritise processes of quality assurance, generating, in some cases, a bureaucratic burden that hinders innovation and experimentation. Media lab can fulfil the role of "hacking" in the university structures to present alternative models in subjects that require a more flexible development, such as the relationship with citizenship and new methodologies and epistemological models.

Following, there exist another model of the lab. Counter-laboratories also experiment and develop through hacking practices. These labs result from the setting up controversies to dispute specific scientific experiments. Independent and sometimes precarious, facing hard difficulties in appropriating the same equipment as institutional laboratories, counter-laboratories adopt strategies of survival, which include for example the so-called opensource hardware $(\mathrm{OSH})$ and open-source software (OSS) practices.

Open-source practices greatly influence the maker movement, as well as the emergence of hackerspaces, contributing to the defiance against capitalism. DIY artists, hackers, makers, and critical agents reflect on the technology's role in reshaping the world's economic and ecologic horizons.

Indeed, the ecological, personal and social relationships become an integral force and a critical proposal to promote alternatives to the technocapitalist industrial society, following Guattari's Three Ecologies (1989).

Therefore, some laboratory practices which do not rely on the institutional model are considered an alternative proposal for the transformation of the industrial process, which is also happening in individual entrepreneurs.

However, in this same context of late-capitalism (tardo-capitalism logic, or techno-capitalism), any alternative practice is also subsumed in the economic system, as Lazzarato (2004) expresses through concepts of precariousness, intellectual work, immaterial labour, and new subjectivities which are totally under the influence of cybernetics and computer control. There is almost no anticapitalist approach because this requires the structural organisation of political and economic systems founded on networks, servers and other technological deployments. Technology created under a scrupulous dependence on the scientific objectifying of hyperstructures (technoscientific laboratories, for instance) is extremely hard to disbelieve, doubt, dissent. It leaves the confronters impressed, without power and resources to contest and dispute its authority, as Bruno Latour refers in the definition of counter-laboratories and sciencein-action.

Also, Jonathan Kemp (2013) states:

"thus makes alternatives subsumed to capital".

However, there is still an in potentia within the capital for cultivating rival forms of production based around what is called "commons-based peer production" (or "social production"). Indeed, more independent productions still use hacking and open-source methodologies, but with their arguments consistently failing to surmount the structural similarities with late capitalism. Then, as the efforts and end-products of cooperation and collaborative production can be readily appropriated and framed by capital, and it is again an expression of a new form of labour rather than a rival to capital itself. So, any rival form ultimately operates in a manner subsumed under capital's 
organisational arm. Although subsuming processes in tardo-capitalism, individuals are using their newly expanded practical freedom to act and cooperate with others, in ways that improve the practised experience of democracy. So, critical culture and community develop fair models of business and laboratories using free software / open-source hardware to share collaboration and selforganisation, as declared by Yochai Benkler (2006). In this regards, the collaborative practices at the intersection between art, science and technology and making use of hacking and DIY methodologies are also set to criticise the phenomena of planned obsolescence produced by Information and Communication Technologies (ICT) companies and the dynamics of desire towards technological devices by consumers. Entering an age of mass extinction brought on by excesses of industrial production and consumption, technological obsolescence becomes a transformative agent in the system. Economically and ecologically, the technological processes face disruption from one hand, but disasters on the other. If obsolescence makes new devices to appear in the market, the same disruptive economy implies a massive environmental catastrophe, which involves affecting the actual climate regime (I use this concept instead of climate change invented by according to Frank Luntz, in the place of "global warming") as technology and innovation directly connect to resources exploitation.

Though being alternative practices to industrial production, happening in individual entrepreneurs who enabled incubators and accelerators leading the movement of "mass entrepreneurship", there is a significant difference between hubs and DIY culture in hackerspaces (and counter-laboratories, too), because of the differences between open culture and mass culture. Entrepreneurs have assimilated innovation and technology to a capitalist economy and the rise of new industrialism. These transform their objects in capital exchange, meanwhile, in DIY / open culture, the transformative possibility to change capitalism relies on the ideology of activating the process, and in the participation of building and sharing knowledge.

\section{THE HYPOTHESIS OF A SONIC LABORATORY}

Around the mid-1990s, the sonic laboratory evolved almost at the same time the media lab was born, during a particular period of consolidation of media practice-based education when projects like the MIT Lab were born with origins in the military; also, a period when new digital technologies started to become institutionalised. Moreover, through the integration of media labs in art institutions, science and technology merged with art and music, and engineers began to approach artistic structures such the Ars Electronica Linz.

Later on, the emergence and the autonomy of the artist arrived thanks to the fragmentation of the market on the internet and other social conditions, such as liberalisation of the academy, facilitation of artists' grants, and R\&D governmental programs. Nowadays, a multitude of artists and developers, musicians as well, are established as autonomous creators favoured by cultural policies of entrepreneurship and autonomy.

The sonic laboratory can be the place in which different strategies from music, to sound art, experimental art and science are successful. The sonic laboratory operates in this direction, offering practices for developing collaborative participation in networks using, for instance, online technologies. Moreover, sonic laboratories have seen the development of tools improved thanks to opensource culture. The instruments makers enjoy a more personal production process, and the artists have more guarantees to produce the instrument they need. Moreover, the sonic laboratory offers a confrontation with the methods of capitalistic technologies, becoming its production more personal and affordable.

Sonic laboratories share many features with media labs but have their character, independence, and a marked idiosyncrasy. Sonic labs are liminal but increasingly important spaces in many contemporary settings. They appear in universities and colleges, between traditional departments and faculties, as well as media labs, or hackerspaces which also appear in basements, warehouses, strip malls and squats. As Jussi Parika and Lori Emmerson (2016) write in What is a Media Lab? Situated Practices in Media Studies, media labs are stable to varying degrees; many have long-term addresses, with an itinerant roster of occupants. Some pop up in one location for a few days and then relocate to another. Sometimes they are even in mobile trucks in the streets, bringing tools and expertise to children in schools and the general public. As clusters of tools and talent streamlined to produce economic value, labs sometimes align with the most ruthless of venture capitalists; in other cases, they are free and open for all to use, disdainful of all commercial motivations.

Progressively the democratisation of labs takes place, freeing technology, through open-source helping to form the actual sonic laboratory, which is currently closely related to individual artists' practices but connected to the community. Following DIY Instruments and White Label Releases by Amit D. Patel (2016), the DIY electronic music instrument's maker community wants to differentiate from utilitarian society and mass-produced items and draw a new experience on sound. Other features that the author appoints 
for DIY culture are self-reliant, anti-systemic, counter-cultural, and, self-sufficient. These features are an example of what is the bases of the sonic laboratory.

The author highlights how DIY instruments are provocatively made to be low cost and often out of throwaway materials. As Patel writes:

\begin{abstract}
"This could be considered a materialist approach in the DIY electronic music-maker scene. The maker scene and benefits of creating a DIY instrument are a challenge, learning new skills, finding intellectual curiosities and exploring the relationship with objects. There is also a focus on doing something and creating something new."
\end{abstract}

DIY is cheap, limited and, self-contradictorily, as well as accessible and exclusive.

Despite the sudden visibility of sonic laboratories, they do have a surprisingly long history. As part of the historical avant-garde, labs were the sites to develop the new materials and aesthetics of technological modernity. They often share a prevailing ideology, tied not just to the neoliberal drive to privatise, innovate and disrupt, but to longstanding modernist ideas about creativity, quantification and the value of scientificity.

One example is the historic Bell Laboratories, a big lab with origins in the XIX century, which set its hegemonic establishment as the possible origin of the sonic laboratory in a proposed history for the laboratory studies in the sound art context.

Sonic labs could also find an origin in radio development, for instance, in the Reeves Sound Laboratory (1946) founded by Hazard Earle Reeves

Jr., an American pioneer in sound and electronics. It was the most significant sound service laboratory in the East and produced a variety of products including tape, film, discs, wire cable, television tubes, cameras and precision recording equipment. Also, the Reeves-Ely Laboratories specifically manufactured a hardened crystal for the U.S. Army Signal Corps while researching advance gunfire control systems and computers, radar and tracking systems, guided missile controls, and aircraft control instruments.

Indeed, sonic laboratories operate influenced by DIY, as seen in the recently inaugurated Laboratorio de Sonido, in LABoral, Gijon, the new media centre for the production, dissemination and exhibition of technological sonic art.

Academic practice links with sonic laboratories, because of the emergence of a new sector born discouraged by the rise of the neoliberal market which has proceeded to privatise culture and transform art into a creative industry. The appearance of the lab has its contextual history in this economic movement that separates from neoliberalism and searches for other possibilities. That is why some of the academic laboratories, media labs mainly, and some sonic laboratories too, are sponsored by universities. For example, Sonic Arts Research Centre (SARC, University of Belfast) and Locus Sonus (École Supérieure d'Art d'Aix-enProvence) are experimental laboratories developed in an academic context and related to the production of the sound works. The first is a sonic laboratory for the listening experience in live concerts, the last, a lab for production and dissemination of sound artworks.

Many laboratories are placed to the arts creative industry such as Laboratorio de Investigación y Producción Musical in Argentina. There is another tendency to fund sonic labs inside the art institutions such in art centres like BANF, Canada, and Hangar, Barcelona, but these sonic labs structures' are around an autonomous economy which facilitates the expression in music-making and the making of sound devices.

Being aware of capitalists' industry and neoliberal market, some labs such Aurality Media Lab in Australia, make their subject of enquiry the ecological and sustainable practice of sound, being this an active resistance in the arts.

\section{AESTHETIC DEVELOPMENT. THE CURATORIAL ROLE IN THE SONIC LABORATORY}

The consequences of an approach of art, science and technology in different areas, such as the university and the artistic involve a liberalisation in the production of musical instruments thanks to the approach of science, engineering and music, which sonic laboratories have contributed to developing. This is why certain sound art practices are related to the so-called DIY movement, emerged from the

1970s as a reaction against the techno-capitalist deployment. With influences of the underground vanguard movements, the handmade culture currently sets as an exponent of what is the opensource culture and movements such as hacker and maker, identified as well as with sonic laboratories. The results of these practices involve an interdisciplinary connection between art, science and technology that improves the creative aspects of contemporary cultural production.

Moreover, sound art practices enrich interconnection with music and engineering. To highlight the DIY practices in front of the capitalist industry represents an immediate change in the prototyping of musical instruments, audio devices and sound objects that have effectively set as a significant creative impulse in our century. 
Nowadays, DIY practices are highlighted versus capitalist industry, promoting a substantial shift in the creation of prototypes, musical instruments and sound objects. This new paradigm of production has evident parallelisms in the aesthetic territory.

This shift happened because artists began developing using methods based on technological innovation, engineering and computation. From its beginning, new media artists have taken the new media art as material to develop, implement, improve and criticise the social context which surrounds them.

Nowadays, the growing use of DIY in instrument making and the creation of sonic prototypes drift away from the type of instruments already categorised in the music industry. Artists and theoreticians who comprehend the practice of sound art inserted in new media take references from technological developments to recreate new apparatus and ways to understand the sonic technologies. This intersection between sound art and media art is absorbing, and it brings new significance to the development of art and technology.

So, aesthetically considering sound devices, their appreciation and value lie in the practising of performance because once exhibited, the objects transform themselves into a fetish commodity. However, why musical instruments and handmade sound device transform into a fetish commodity?

According to Jonathan Sterne (2014), fetishes allow visualising what is unknown. So, when its appearance judges music instruments, they acquire a magical dimension. Music and musicianship are mystified and separated from everyday life, nonconsidering the lived experience of most instruments. This is because a tendency in instrument-making hides the machinery, the functional control and efficient operation of the instrument. This attribution of magic comes when a moment of distance is given to instrumentality, either at the time of observation when practical knowledge is not available.

The moment of distant reflection adds a spiritual dimension to the instrument because, in observation, there is a lack of practical functions, so the object becomes mystified, fetishised. Sarah Ahmed (2006) writes about technologies which are no longer ready for action. An experience of being unable to use a thing, or distance at the moment of use, leads to the attribution of properties, qualities and values to the thing itself.

This is a failure in the symbolic consideration at the moment of non-use of the object. The exhibition and exposure of musical object contribute to transforming into a fetish commodity. Based on observation and experimentation, separated from the context of musical practice and performance, contextualised as objects of solemn contemplation, and placed as works of art in the museum context, these transform into consecrated objects, when they are in reality ready for interaction, inviting to touch, hearing, engaging, and breaking down the separation between performer and audience.

Indeed, the transformative economy of art institution does not rely on the exhibition, but in the force of activating through performance. Then, passive audiences disappear, changing the pillars of classical aesthetics, based on the Kantian ideology. Contrary, the art market establishes barriers that have not been operative in the control of developing experiences properly human and dictating the force of the market as a medium to survive. Instead, DIY economies propose a mechanism of production based in processual order that appoints to obsolescence and extinction as some fatal errors in the capitalist system. The transformative capabilities of DIY do not rely on objects' placement in the context of a museum and exhibiting them with an emphasis on the visual, just because musical instruments and other sound constructions have the potential to function a little differently from other sorts of creative arts.

Promoting participation in workshops, the sonic laboratories dissociate from the institutional space of the museum, allied with passive and contemplative aesthetics. Although many museums are nowadays aware of this, the use of contemplative practices roots them in classically forged aesthetics. Recently Tate Modern has offered more interactive and dynamics works in the exhibition, but the transformative function of the laboratory could change the museum into a learning machine. As the lab's communitarian practice bases on shareable knowledge and pedagogic aspects, it will be necessary to include these parameters in the contemporary museums, which is happening using new media art practices and audience's participation.

Moreover, the practices developed in the sonic lab enhance the new media curating, for instance, setting the exhibition space as an experimental sonic laboratory. The labs' forms are those of the music studio, the studio where artistic experiments co-live along with various practices and machines, electronic synthesisers, films, audiotapes, and plenty of other apparatus, as well as sound objects, coding practices, algorithmic calculations and software development.

The procedural way in which sonic laboratories engage with creative work is a dynamic, an open process in transdisciplinary experimentation. To approach these manners of working into the exhibition space recreating and re-enacting sonic laboratory practices in an exhibition will conduct results understood as exhibiting the lab. However, how useful it is? Is this the site of display and the 
site of production? Is it possible to expose the work in process?

One of the exponent practices resembling what is called curating the sonic laboratory is the maker fairs, that exhibit audio devices, DIY instruments, and modular synthesiser. Another example is the Sonar Festival that adopts expositive practices of the prototypes developed by artists, engineers, musicians, and others, in a hybrid way between the exhibition, the showroom, and the live demonstrations that are not live concerts. A showroom where the audiences can experiment, learn and enjoy new trends in electronic music, but favouring products created from DIY ethics, but also connecting within the science and technology network linked to the industry, indeed contradictorily.

The sonic laboratory offers new opportunities to the exhibition in the art gallery, transforming it into an experimental laboratory where applied arts mediated through interdisciplinary work with science, produce experiments able to be repeated and measured. This is a socially constructed structure that permits to give answers to new creative developments. Following Bruno Latour, in the lab, art, science and technology confuse with a critical and cultural activity, becoming the lab a site of mediation, in between theory and practice, discursive and non-discursive. Latour notes that labs in the art approach to the science lab, extend the material practices into the exhibition place, and proceed to experimentation, work in process, and an open-ended process to build knowledge.

The result, the exhibition research lab, is present in many other labs, from maker spaces to fab labs, and in the so-called sonic laboratories, increasingly abundant. So to address the role of electronic arts, sonic arts, audio arts, and sound arts in the space of the lab critically, positions the role of the sonic laboratory in the network of media labs, hacker zones, maker spaces, humanities labs, fab labs, tech incubators, innovation centres, hack labs and media archaeology labs.

To sum up, sonic laboratories in the art scene are mainly places for production, not adopting strategies from the industrial process (which also includes processes of distribution and execution). So, if the process of the exhibition can transform the music device in fetish commodities, curating the lab is a solution through exploring and experimenting. It can be an integrative process of the production and exhibition without becoming part of an industrial process. This happens in certain curatorial practices when the exhibition transforms, and instead of contemplation, participants in the exhibition can interact and explore the works as if they were in a lab. So, curating the lab will be the end of a research process which investigates about
DIY practices in music-making devices and sound objects.

\section{REFERENCES}

Ahmed S. Queer Phenomenology: Orientations, Objects, Others. Durham, NC: Duke University Press. 2006.

Artaud, A. El Teatro de la Crueldad. Ciencia, Poesía Y Metafísica. Editorial La Pajarita De Papel. 2019.

Benkler, Y. The Wealth of Networks. New Haven: Yale University Press. 2006. [Online] Available at

http://benkler.org/Benkler_Wealth_Of_Networks. pdf [Accessed: 15-7-2019].

Bratach P. Why Do Open Source Projects Fork? 2017. [Online] Available at https://thenewstack.io/ open-source-projectsfork/ [Accessed: 14-06-2018].

Collins, N. Handmade Electronic Music. The Art of Hardware Hacking. London \& New York: Routledge. 2006.

Dyson, F. Sounding New Media: Immersion and Embodiment in the Arts and Culture. CA: University of California Press, 2009.

Fritz, D. Grey Area, Zagreb. [Online] Available at http://sivazona.hr/start [Accessed: 20-02-2018].

García, M. (2015). Medialab-Prado: retos del presente. LabMeeting 2015. Medialab Prado. Madrid. 2015. [Online] Available at https://www.medialab-prado.es/noticias/lab meeting2015-madrid-documentacion-audiovisual [Accessed: 23-12-2016].

Guattari, F. The three ecologies. London: Bloomsbury Academic. 2014.

Kemp, J. The Crystal World: Executing a New Media Materialism. PhD Dissertation: University of Westminster. 2013.

Knorr-Cetina, K. The manufacture of knowledge: an essay on the constructivist and contextual nature of science. Oxford New York: Pergamon Press. 1981.

Krysa, J. Exhibition as Lab. Erkki Kurenniemi in 2048, Documenta 13. Media Art Histories. 2016. [Online] Available at http://pl02.donauuni.ac.at/jspui/ handle/10002/746 [Accessed: 2706-2018].

Kuni, V. Abstract for the lecture within the conference Screening Science. 2005. In Johannes Lenhard, Warhols Factory - A Laboratory. [Online] Available at http://www.grin.com/en/e-book/142943/ warholsfactory-a-laboratory [Accessed: 28-082017]. 
Latour, B. Give Me a Laboratory and I will Raise the World. In: Knorr-Cetina, K. and Mulkay, M., eds. Science Observed: Perspectives on the Social Study of Science. London and Beverly Hills: Sage. 1983.

Latour, B. Science in Action. How to follow scientist and engineers through society. Cambridge, Massachusetts: Harvard University Press. 1987.

Latour, B. and Woolgar, S. Laboratory Life, The Construction Of Scientific Facts. New Jersey, Princeton: Princeton University Press. 1986.

Lazzarato, M. From Capital-Labour to Capital-Life. Translated by Valerie Fournier, et al. Ephemera Journal, 4, 3. [Online] Available at http://www.ephemerajournal.org/sites/default/file s/43lazzarato.pdf [Accessed: 07-10-2019]. 2004.

McLuhan M. Understanding Media. The extensions of man. London and New York: Gingko Press Inc. 2003.

Moskow, M. The Age of Advertising: Reeves Sound Laboratories (1943-1944). History, at Random. The Past In The Present. 2017. [Online] Available at http:// thepastpresented.com/index.php /tag/reevessoundlaboratories/ [Accesed: 22-04-2018 ].

Parika, J. and Emmerson, L. What is a Media Lab? Situated Practices in Media Studies. 2016. [Online] Available at https://whatisamedialab. com/ [Accesed: 22-04-2018 ].

Patel, A. DIY Instruments and White Label Releases. In: eContact! 18.3 - Sonic DIY: Repurposing the Creative Self. Montréal: Communauté électro-acoustique canadienne / Canadian Electroacoustic Community. 2016.
[Online] Available at http://econtact.ca /18_3/patel_whitelabel.html [Accesed: 2016].

Pickering, A. Science as Practice and Culture. Chicago, University of Chicago Press. 1992. [Online] Available at https://www.research gate.net/publication/37688422_Science_as_Pra ctice_and_Culture [Accessed: 2016].

Romero-Frías, E. and Robinson-García, N. Social Labs in Universities: Innovation and Impact. In: Comunicar, n. 51, v. XXV, Media Education Research Journal. 2017. [Online] Available at http://eprints.rclis.org/31099/1/c5103en.pdf [Accessed:27-09-2017).

Rowan, J. Cultura Libre de Estado. Madrid: Traficantes de Suenos. 2016.

Ruiz Martín, J., \& Alcalá Mellado, J. Los cuatro ejes de la cultura participativa actual. De las plataformas virtuales al medialab. In: Revista ICONO14 Revista Científica De Comunicación Y Tecnologías Emergentes, 14(1), 95-122. 2016. [Online] Available at https://doi.org/10.7195 /ri14.v14i1.904 [Accessed: 10-07-2019].

Sterne, J. The Magic in instruments. Music technologies and commodity fetishism. In: Celant, G. Art or Sound. 2014.

Tanaka, A. Situating within Society: Blueprints and Strategies for Media Labs. In: Angela Plohman, ed. A Blueprint for $a$ Lab of the Future. Eindhoven: Baltan Laboratories. 2011.

Vinck, D. Back to the laboratory as a knowledge production Space. In: Revue d'anthropologie des connaissances. 2007/2 (Vol. 1, n 2). 2007. [Online] Available at https://www.cairn.info/ revueanthropologie-des-connaissances-2007-2page160.htm [Accessed: 28-08-2017]. 